\title{
Diversities in timing of sexual debut among Nigerian youths aged 15-24 years: parametric and non-parametric survival analysis approach.
}

\author{
Adeniyi Francis Fagbamigbe ${ }^{1,2}$, Erhabor Idemudia ${ }^{1}$
}

1. School of Research and Postgraduate Studies, North West University, Mafikeng, SouthAfrica

2. Department of Epidemiology and Medical Statistics, Faculty of Public Health, College of Medicine, University of Ibadan. Nigeria

\begin{abstract}
Objective: This study examined gender, generational, cultural and social diversities in timing of sexual debut among Nigerian youths and determined factors influencing the timings.

Methods: We extracted data of respondents aged 15-24 years from 2012 Nigeria nationally representative data. The outcome of interest was time at sexual debut while predictors included residence, marital status, zones, education, religion, age at first marriage. Data was censored, cox proportional hazard and generalized gamma models were used to model age at sexual debut with $\mathrm{p}=0.05$.

Results: The median survival time of sexual debut was 19 years, female youths were twice as likely to begin sexual activities than their male counterparts, $\mathrm{HR}=1.99,1.87-2.11$ while uneducated youths were more than twice likely to have earlier sexual debut than those with higher education, $H R=2.19,1.95-2.25$. Likelihood of having had sexual debut was about 30\% higher among those aged 20-24 years than those aged 15-19 years, $H R=1.27,1.19-1.36$.

Conclusion: Females from poor households mostly in rural areas with no education and who married early in life were more likely to have earlier sexual debut. Both teenagers and young adults are on different trajectories of sexual debut but both urgently need sexual and reproductive health education to delay sexual debut.
\end{abstract}

Keywords: Sexual debut, survival analysis, Nigeria, generalised gamma, wealth.

DOI: https://dx.doi.org/10.4314/ahs.v17i1.7

Cite as: Fagbamigbe AF, Idemudia E. Diversities in timing of sexual debut among Nigerian youths aged 15-24 years: parametric and non-parametric survival analysis approach. Afri Health Sci. 2017;17(1): 39-51. bttps:/ / dx.doi.org/10.4314/ahs.v17i1.7

\section{Introduction}

Globally, early sexual debut among adolescents and consequent teenage pregnancy remains a recurring ${ }^{1-5}$ and a seemingly unsurmountable social and public health problem. This is due to the fact that early initiation into sexual activities is not unlikely to be non-consensual and most likely to be subsequently regretted ${ }^{5,6}$. One of the major changes in people transiting from childhood to adolescence is sexuality. Several adolescents consider first sexual experience to be an experience that signifies their transition to adulthood and they often approach first intercourse with a combination of anticipation and anxiety ${ }^{7}$. The transition has been described as a period of rapid

\section{Corresponding author:}

Fagbamigbe Adeniyi Francis,

School of Research and Postgraduate Studies, North West University, Mafikeng, SouthAfrica

Tel: +2348061348165

Email: franstel74@yahoo.com change when young adolescents usually seek stable point of reference from peers ${ }^{8}$. This has led to considerable shortened age at which adolescents begin sexual intercourse, both in the developed and developing countries in recent decades ${ }^{9,10}$. The sexual and reproductive health of adolescents and young adults especially in developing countries is therefore in need of urgent attention.

Early age at sexual debut had made the girl child more vulnerable to early pregnancy and marriage and sexually transmitted diseases than the boys worldwide, especially in Africa ${ }^{1,11,12}$. Provision of enabling and supportive environments for adolescents to delay sexual debut and practice safer sex is vital for the Millennium Development Goals (MDGs) on child health, mortalities, poverty, sexual equality, maternal health, and HIV/AIDS to be achieved $^{13-15}$. Although there is no distinct universal trend towards earlier sexual intercourse, there has been reported worldwide shift towards later marriage in most countries and this has resulted in increased rate of pre-marital sex ${ }^{5}$ which might shorten age at sexual debut. This has been found to be much significantly higher in developed

African Health Sciences Vol 17 Issue 1, March, 2017 
countries than in developing countries and among males than females.

The consequences of early sexual debut include the risk of unintended pregnancy, sexually transmitted infections (STIs) including Human Immunodeficiency Virus (HIV) and increased poverty ${ }^{1,16}$. Pre-marital pregnancy arising from early sexual activities eventually results in either abortion or early motherhood on the part of the female and early fatherhood for males. Neither abortion nor early parenthood is pleasant. While abortion may be carried out in an unsafe manner therefore leading to life-long problems or even death, teenage parents and their children face greater risks of adverse health and medical outcomes $^{17}$, educational and socio-economic consequences than do older parents and their children ${ }^{18}$.

It has been suggested that early sexual debut increases young peoples' risk for HIV and other STIs ${ }^{1}$. People who started sexual activity early are more likely to demonstrate high-risky sexual behaviour ${ }^{2}$. Youths aged 15-24 years are particularly vulnerable to HIV and other STD in Nigeria with a HIV prevalence of 2.9\% among those aged 15-19 years and $3.2 \%$ in the $20-24$ years age bracket ${ }^{19}$. A recent study estimated that about one in four HIV incidents are among youths aged 15-24 years ${ }^{20}$ and HIV prevalence among youths aged 15-24 years in South Africa is 7.1\% with females aged 20-24 years topping the range with $17.1 \%{ }^{21}$. Stone et al found about one-half of youths who had ever had sex had their first sexual experience before their 16th birthday, 47\% and 51\% among males and females respectively ${ }^{22}$. Delaying sexual debut is one of the surest way of fighting the scourge of HIV/STIs among young people $e^{21,23}$.

Besides the health consequences of teenage child bearing, the social implications are far over reaching among adolescent mothers worldwide ${ }^{16}$. Early pregnancy and child bearing, which leads to children nursing children, truncated educational opportunities, abandonment by partners, poor job opportunities, lower potential future earnings, large family sizes, has been linked to greater population growth and higher likelihood of poor maternal outcomes ${ }^{11,12}$.

As of 2007, the global median age at sexual debut was 18.4 years, ranging from 23.0 years in Malaysia to 15.6 years in Iceland ${ }^{24}$. In 2012, 37\% of the females and $20 \%$ of the males aged 15-19 years in Nigeria had engaged in sex ${ }^{19}$ compared with the 2007 findings of $43 \%$ for female and $22 \%$ for male ${ }^{25}$. The trend analysis of median age at first sex for persons aged 15-24 years showed 17 years for both males and females in 2012 compared with a lower 16 years reported in 2007. This was much lower than the 19.7 years reported for same year in a report on age at first sexual intercourse across 44 countries including Iceland $^{24}$. Similar age at first sexual intercourse was found in Ethiopia, wherein the age increased from 16.5 years in 2005 to 17.1 years in 2011 for females and from 21.1 to 21.2 years over the same period for the males ${ }^{12}$. However, a USA based survey on family growth showed that a sizeable proportion of adolescents didn't have their first intercourse until after the teenage years and that most teens who had it during the teenage years did so late at 18-19 years ${ }^{7}$. An earlier study which used data from the same survey found that about $27.5 \%$ of youths aged $15-17$ years had had intercourse compared to about $63 \%$ among those aged 18-19 years ${ }^{26}$ but a younger age 17 years at sexual debut was found among US heterosexual university students aged15-24 ${ }^{27}$. Regional, gender and location differences have also been reported in median age at first sexual intercourse in Nigeria ${ }^{19,23,25,28}$.

Early pregnancy and child bearing during the teenage years, which are direct outcomes of early sexual debut, often results from and in social exclusion ${ }^{22}$, low parental socio-economic status, poor educational achievement and being in foster care or in a group home ${ }^{22,29}$. Literature is replete on the fact that age, gender, residence, educational level, knowledge on HIV, economic status, watching pornography, and alcohol utilization affects the timing of sexual debut among youths $s^{1,4,10-12,16}$. In addition, sexual abuse and violence could have negatively affected age at sexual debut as sexual abuse victims are more likely to have earlier sexual debut. Youths have been reported to have more increasing migration from rural areas to urban areas and therefore increasing the risks of exploitation, non-consensual sexual intercourse and sexual violence $^{30}$ which could further shorten age at first sexual intercourse.

Globally, the existing empirical and theoretical literatures on the risk factor of timing of sexual debut among youths include place of residence, age, geographical zones of residence, education, religion, residence, wealth status, age at first marriage among others ${ }^{1,4,10-12,16,31-33}$ and are therefore included as co-variates in this study. Specifically, Tilahun 
et al ascribed the 17.1 years median age at sexual debut among Ethiopian women to the early age at first marriage and concluded that "for most girls, marriage drives sexual debut". Also access to better education in urban areas and belonging to a more affluent homes might delay sexual debut ${ }^{1,733}$. Other determinants might include marriage status of parents as children of divorced or widowed parents might have sex earlier than those whose parents are still married ${ }^{22,29,33,34}$. Socio-cultural differences and settings such as Islamic societies where girls are betrothed early in life have also been identified to affect age at first sexual experience in some countries ${ }^{32,33,35}$.

While research efforts have focussed on identifying factors that influence early sexual debut and increasing need for programmatic strategies to modify teenage sexual behaviour ${ }^{1,16,17}$, little has been documented in the areas of progression of youths into sexual activities and in understanding the timing of the age at sexual debut and its determinants, especially in Nigeria. Unacceptable prevalence of unintended pregnancy, abortion, HIV/AIDS and other sexually transmitted infections, truncated educational and job opportunities among youths have made it very important to understand the timing of sexual debut and determine the risk factors of timing of sexual debut. The aim of this study was examine the timing of the progression of youths in Nigeria for sexual debut and to determine the factors affecting the timing. The outcomes of this study will provide evidence-based information to policy makers and other stakeholders in youths' sexual and reproductive health.

\section{Methods and materials \\ Study design and setting}

This study used data from the 2012 National HIV\&AIDS and Reproductive Health Survey NARHS Plus II (2012). The cross-sectional and nationally representative data provided information about demographics, sexuality and other reproductive behaviour of men and women of reproductive age in Nigeria. It used a four-stage sampling procedure. First stage was selection of local government areas on rural-urban basis from every state and the Federal Capital Territory (FCT), then selection of clusters, selection of households and finally the selection of the individuals. A total of 35,520 men and women age 1549 were identified as eligible for individual interviews of which 31,235 were successfully interviewed.

\section{Data}

We extracted data provided by 10,091 respondents aged 15-24 years. The information extracted included background characteristics age, religion, education etc. and other sexual and reproductive history, time of first sexual intercourse, age at first marriage. The outcome variable in this study was the time in years at sexual debut while place of residence, age, geographical zones of residence, education, religion, residence, age at first marriage were the predictors.

\section{Operational definitions}

Sexual debut: first sexual intercourse; youths: persons aged 15 to 24 years; teenagers: persons aged 15 to 19 years; young adults: persons aged 20 to 24 years

\section{Statistical analysis}

Basic descriptive statistics was used to describe the sample and the characteristics of the respondents and significance determined using a Chi-square test of association. Data was weighted to adjust for differences in population in each state and FCT. Bivariate and multivariate Cox Proportional Hazard (CPH) and Generalized Gamma (GG) models and were used to determine factors associated with timing of sexual debut using Hazard Ratios (HR) and adjusted Hazard Ratios (aOR) and Time Ratio (TR) and adjusted Time Ratios (aTR) respectively. Model fit was assessed using goodness of fit test. Stata version 12.0 was used for data analysis. Significance of all statistical tests were determined at 5\% level.

\section{Rationale for use of survival analysis}

Retrospective reproductive history of both men and women follows the fundamental principle of survival analysis otherwise called "history of event". The event of interest in this study is age at first sexual intercourse. Survival analysis remains the best choice when describing time duration to occurrence of an event of interest in which case, all participants are susceptible to the event but not everyone has necessarily experienced the event. The study might come to an end without every participant experiencing the event of interest, some could be lost to follow up while some could withdraw then the event of interest is censored among these groups of participants who did not experience the event and are therefore included in the analysis. 
In this study, we censored individuals who have not had sexual experience as of the survey date. The "survival time" among those who have had sex is their age as of first sex while the survival time is the current age as of the survey date for those who have not had sexual experience. The survivor function $(\mathrm{S}(\mathrm{t}))$ and hazard function $(\mathrm{h}(\mathrm{t}))$ were determined using Kaplan Meier estimates. The functions shows the probability that an individual "survives" longer than some specified time t before having first sex and the instantaneous chance per unit time t to have sexual experience, given that the individual had not had sex before time t. Survival and hazard function are mathematically denoted by

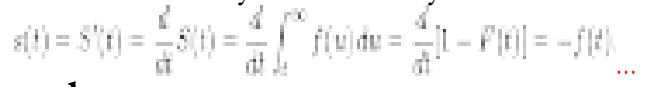

and

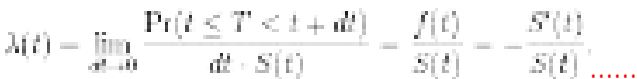

respectively. The Kaplan-Meier estimates of $\mathrm{S}(\mathrm{t})$ were obtained from

$$
s(t)=\prod_{j=1}^{k} \frac{\left(n_{j}-d_{j}\right)}{n_{j}}
$$

where $n_{j}$ is the number of participant observed at time $t_{j}$ and $d_{j}$ is the number of participant that experienced that has had sex at time $t_{j}$. The incidence rate (IR), the probability that an individual would have had first sex at time $t_{k+1}$ given that he/she has not had first sex by time $t_{k}$ was also determined. Log-rank test was used to test the equality of the survival functions.

The Cox Proportional Hazard $(\mathrm{CPH})$ regression, developed by David $\mathrm{Cox}^{36}$ was used to model the timing of first sex. CPH, a semi-parametric approach, assumes that the effect of a unit increase in co-variate is multiplicative with respect to hazard rate. The model is measured in terms of $\mathrm{h}(\mathrm{t})$ and it produces the hazard at time $t$ for an individual with a given specification of a set of independent variables denoted by $\mathrm{X}$ to predict individuals' hazard. The model assumes the relationship for one co-variate where $h_{0}(t)$ is the baseline hazard function, $x_{i}$ are the co-variates and $\beta_{i}$ are the coefficients. We also

African Health Sciences Vol 17 Issue 1, March, 2017 stratified Cox regression estimates for each of the independent variables.

The hazard ratio (HR), expressed as the exponentials of the coefficients shows whether the coefficients would be statistically significant or not. An $\mathrm{HR}>1$ implies more exposure to event of interest, $\mathrm{HR}<1$ means low exposure while $\mathrm{HR}=1$ has no effect on the exposure. Log rank test was used to compare the survival experience between different groups under study.

We used the Generalized Gamma (GG) survival distribution model one of the accelerated failure time models to complement the $\mathrm{CPH}$. Besides being a parametric model, it has the advantage of more precise coefficients and easy interpretation over the Cox model, a semi- parametric model. In parametric models, direct effects of the explanatory variables on the survival time are easily measured through "time ratio" instead of hazard. For each co-variate in the model, a time ratio (TR) value greater than one implies that an individual experiences the event at a later timing and vice versa.

\section{Ethical consideration}

The ethical approval for the survey was sought and obtained from the (Institutional Review Board IRB) of the National Institute of Medical Research prior to commencement of the survey. Oral or written informed consent was sought from each respondent before a questionnaire was administered as earlier documented ${ }^{19}$.

\section{Results}

Of the 10,091 youths aged 15-24 years studied, half 50\% were $15-19$ years old. About half $52 \%$ of the youths had had sex; 31\% among teenagers (15-19 years) and 73\% among young adults aged 20-24years. The highest proportion of youths with sexual experience was found in the North East (57\%) and lowest in South East (38\%), $(38 \%)$ among males, female (63\%), 31\% among never married, 98\% among the married youths, urban $47 \%$ and $55 \%$ in the rural area. In all, $16 \%$ had had sex before attaining age 15 years while $69 \%$ had sex between ages 15 19 years. Those that had sex and categories of age at first sexual intercourse were significantly associated with each of the respondents' characteristics (Table 1). 
Table 1: Distribution of respondents' sexual experience and age at $1^{\text {st }}$ sex

\begin{tabular}{|c|c|c|c|c|c|}
\hline \multirow[t]{2}{*}{ Characteristics } & \multirow[t]{2}{*}{$\mathbf{n}$} & \multirow{2}{*}{$\begin{array}{l}\text { Had had sex } \\
\%\end{array}$} & \multicolumn{3}{|c|}{ Age at sexual Debut ${ }^{\wedge}$} \\
\hline & & & $<15$ & $15-19$ & $20+$ \\
\hline \multicolumn{6}{|l|}{ Age years } \\
\hline $15-19$ & 5087 & $* 30.8$ & $* 25.6$ & 74.4 & 0.0 \\
\hline $20-24$ & 5004 & 73.3 & 11.5 & 67.3 & 21.3 \\
\hline \multicolumn{6}{|l|}{ Zone } \\
\hline North Central & 2547 & $* 54.1$ & $* 13.1$ & 70.5 & 16.4 \\
\hline North East & 1355 & 56.9 & 16.7 & 72.6 & 10.8 \\
\hline North West & 2484 & 54.6 & 23.7 & 63.0 & 13.3 \\
\hline South East & 763 & 38.0 & 8.0 & 70.8 & 21.2 \\
\hline South South & 945 & 53.6 & 11.7 & 76.6 & 11.7 \\
\hline South West & 1997 & 46.8 & 11.1 & 70.2 & 18.7 \\
\hline \multicolumn{6}{|l|}{ Residence } \\
\hline Urban & 3465 & $* 46.6$ & $* 11.6$ & 69.2 & 19.2 \\
\hline Rural & 6626 & 54.7 & 17.6 & 69.5 & 12.9 \\
\hline \multicolumn{6}{|l|}{ Economic status } \\
\hline Lowest & 4664 & $* 56.5$ & $* 21.0$ & 68.4 & 10.6 \\
\hline Middle & 1923 & 49.3 & 13.5 & 71.1 & 15.4 \\
\hline Highest & 3483 & 47.0 & 8.8 & 70.0 & 21.2 \\
\hline \multicolumn{6}{|l|}{ Education } \\
\hline No Education & 2091 & $* 71.0$ & $* 26.4$ & 64.9 & 8.8 \\
\hline Primary/Qur'anic & 1822 & 83.4 & 19.5 & 66.9 & 13.6 \\
\hline Secondary & 5416 & 42.6 & 9.8 & 74.9 & 15.2 \\
\hline Higher & 744 & 62.1 & 5.7 & 60.3 & 34.0 \\
\hline \multicolumn{6}{|l|}{ Sex } \\
\hline Male & 4433 & $* 38.0$ & $* 11.6$ & 69.3 & 19.1 \\
\hline Female & 5658 & 62.8 & 17.6 & 69.4 & 13.0 \\
\hline \multicolumn{6}{|l|}{ Religion } \\
\hline Islam & 4952 & $* 53.4$ & $* 22.1$ & 65.0 & 13.0 \\
\hline Christian & 4998 & 49.9 & 9.1 & 73.8 & 17.1 \\
\hline Others & 141 & 68.4 & 7.6 & 79.9 & 12.4 \\
\hline \multicolumn{6}{|l|}{ Tribe } \\
\hline Hausa/Fulani & 2949 & $* 54.9$ & $* 24.9$ & 63.0 & 12.1 \\
\hline Yoruba & 1058 & 41.6 & 6.9 & 70.0 & 23.1 \\
\hline Igbo/Ibiobio & 2046 & 47.0 & 11.0 & 70.1 & 18.9 \\
\hline Others & 4034 & 54.9 & 12.7 & 73.8 & 13.6 \\
\hline \multicolumn{6}{|l|}{ Age at 1 st Marriage } \\
\hline Never & 6762 & $* 31.2$ & $* 11.6$ & 71.8 & 16.6 \\
\hline$<15$ & 530 & 98.4 & 83.8 & 13.0 & 3.2 \\
\hline $15-19$ & 1619 & 99.4 & 4.2 & 95.2 & 0.7 \\
\hline $20+$ & 579 & 98.3 & 2.0 & 35.3 & 62.7 \\
\hline \multicolumn{6}{|l|}{ Marital status } \\
\hline Currently Married & 3065 & $* 97.3$ & $* 18.6$ & 67.5 & 13.9 \\
\hline Formerly Married & 106 & 80.3 & 18.2 & 74.1 & 7.7 \\
\hline Never & 6762 & 31.2 & 11.6 & 71.9 & 16.6 \\
\hline Total & 10091 & 51.9 & 15.7 & 69.4 & 14.9 \\
\hline
\end{tabular}

The proportion of respondents aged 20-24 years that were initiated into sexual activities every year starting from age 9 were higher than among 15-19 years old respondents. Also the proportions of females initiated into sexual intercourse at each age were higher than among male respondents. Cumulatively, the proportion who had been engaged in sexual activities by each age examined were higher in females than in males as shown in Figure 1. 
Figure 1: Distribution of age at sexual debut among Nigeria youths by sex

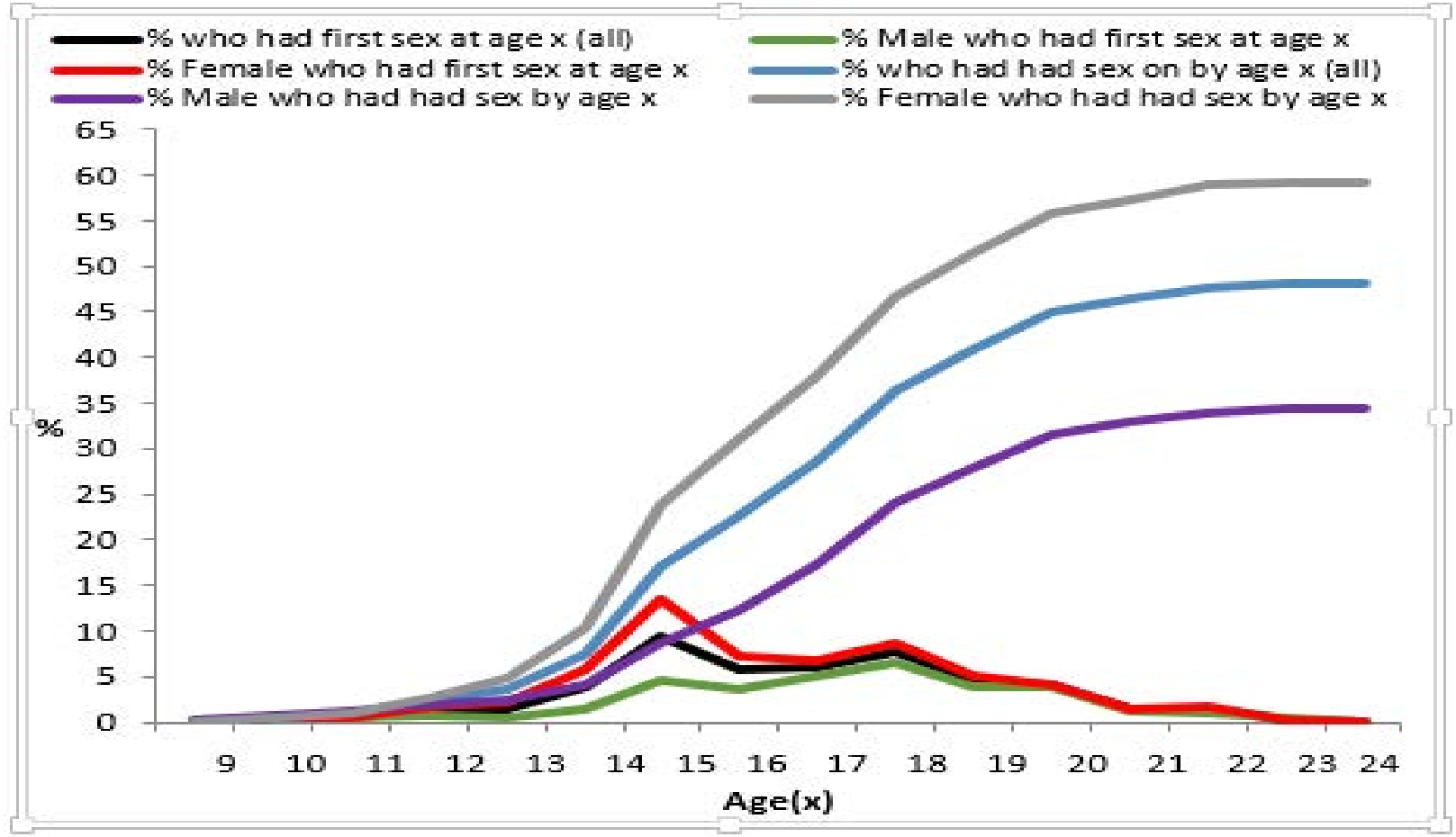

Note: 642 that provided invalid date of sexual debut were excluded

The outcome of survival analysis of timing of initiation into sexual activities showed that by age 15 , nearly $18 \%$ of all respondents would have had sex at least once.
Probability of sexual debut was higher among females than males across all ages except at age 13 and 14 years when they had similar probabilities Figure 2.

Figure 2: Survival analysis of first sexual experience among all respondents by gender
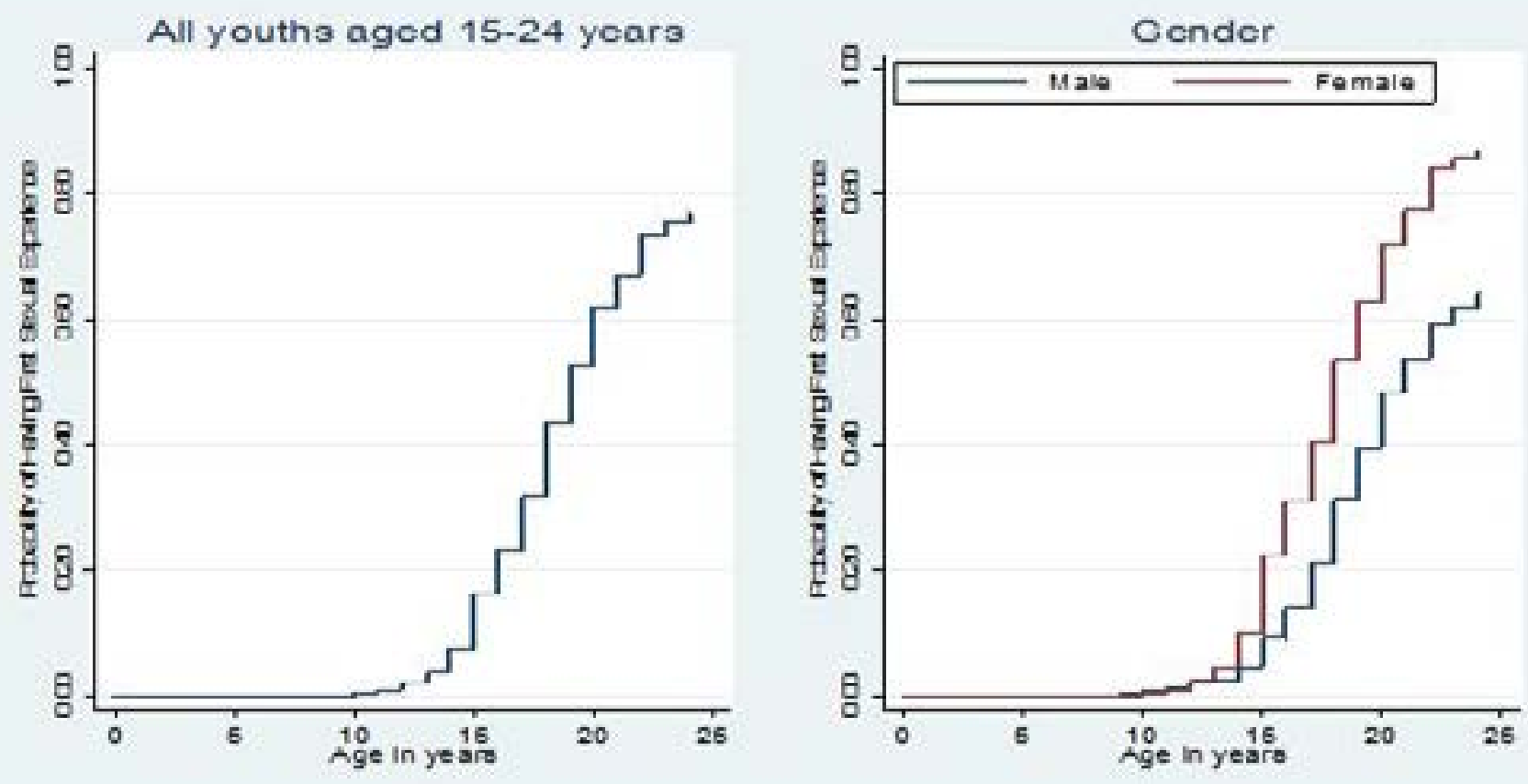
The probabilities of sexual debut among the male respondents by their socio-demographic characteristics were explored. Considering age, male respondents aged 20-24 years had higher probabilities of having engaged in sexual intercourse than those aged 15-19 years. There doesn't seem to be significant differences in sexual debuts among the male respondents on the basis of the economic status they belong Figure 3 .

Figure 3: Probabilities of Sexual debut among Male respondents according to some selected socio-demographic characteristics

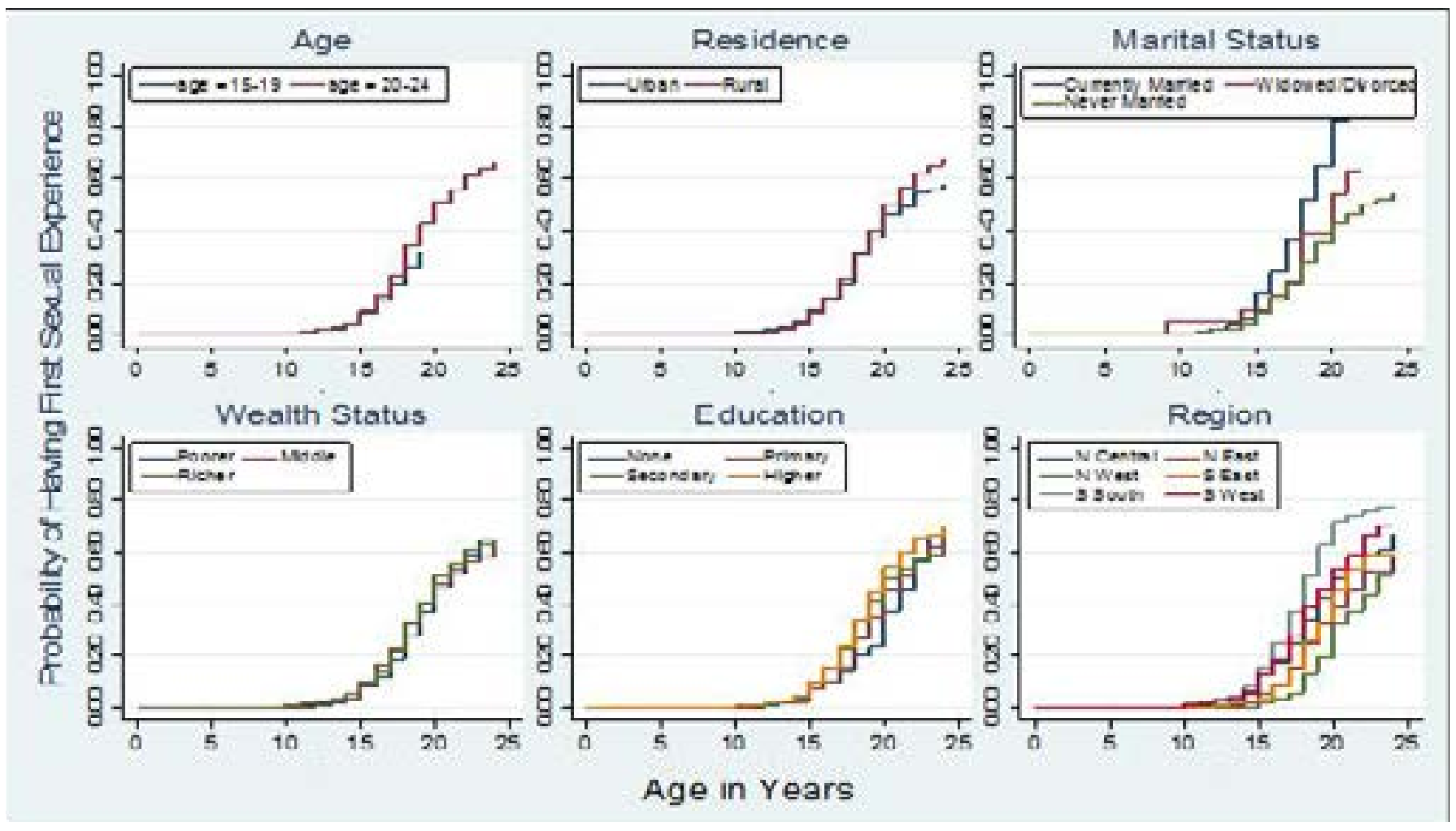

Female youths living in rural areas had higher probabilities of sexual debut than the males as they grew older. Similarly, the sexual debut among females with no formal education and those with only primary education had higher chances of sexual debut than females with secondary and higher education. Females in the South West region had lowest likelihood of commencing sexual debut than females from other regions as they got older (Figure 4). The test of equality of survival functions of the variables considered among all the youths and also across gender lines were significantly different except the survival functions of the economic status of the males which were not statistically different. 
Figure 4: Probabilities of Sexual debut among Female respondents according to some selected socio-demographic characteristics

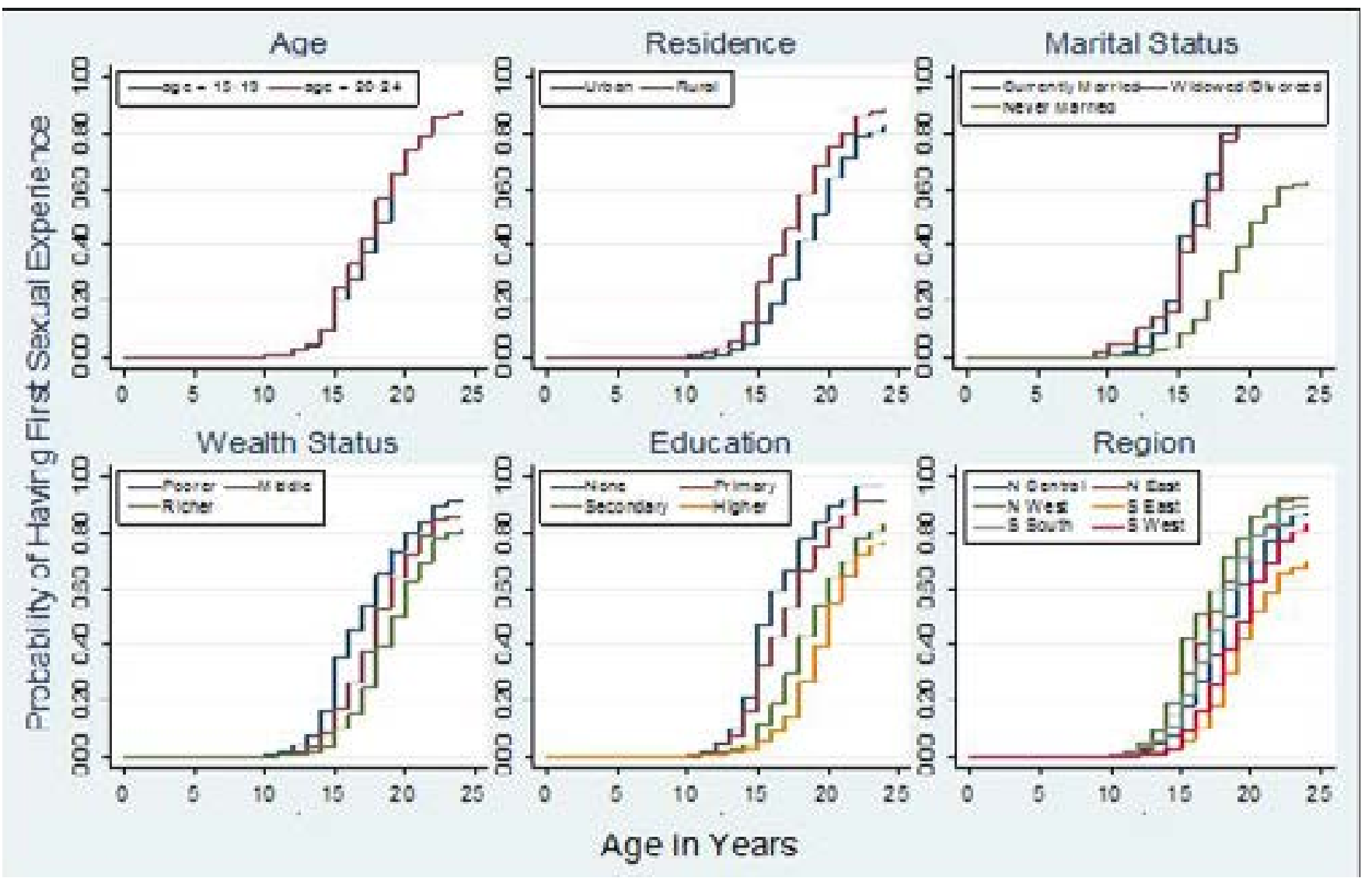

The median survival time of sexual debut was 19 years, 17 years among youths aged 15-19 years and 19 years among those aged 20-24 years (Table 2). The bivariate $\mathrm{CPH}$ model showed that the Hazard Ratio (HR) of age at first sex was four times higher among those that were currently married compared with those who were never married (HR=3.96, 95\% CI: 3.73-4.20). Likelihood of sexual debut was about $30 \%$ higher among those aged 20 24 years than those aged $15-19$ years $(\mathrm{HR}=1.27,95 \% \mathrm{CI}$ : 1.19-1.36), 50\% higher among youths from households with lowest economic status than those with highest economic status households ( $\mathrm{HR}=1.49$, 95\% CI: 1.40-1.60) and about $40 \%$ higher among those in rural areas than in urban areas $(\mathrm{HR}=1.37,95 \% \mathrm{CI}: 1.29-1.47)$. The GGM showed that females are about $11 \%$ times more likely to start sex earlier than the males ( $\mathrm{TR}=0.89$, 95\% CI: 0.88 $0.90)$.

The multiple CPH and GG models while controlling for other variables showed that there are higher odds of initiation into sexual activities among young adults than the teenagers $(\mathrm{aHR}=0.7,95 \% \mathrm{CI}: 0.74-0.85)$ and $(\mathrm{a} T \mathrm{TR}=1.06$, 95\% CI: 1.05-1.07). The females were more likely to assume sexual activities earlier than the males $(\mathrm{aTR}=0.97$, 95\% CI: 0.95-0.98). The GG model also showed that the rural dwellers significantly begin sexual activities earlier than those from the urban areas (aTR $=0.98,95 \%$ CI: 0.97-0.99). 
Table 2: Unadjusted and Adjusted Determinants of timing of age at first sex among Nigerian youths

\begin{tabular}{|c|c|c|c|c|c|c|}
\hline \multirow[b]{2}{*}{ Characteristics } & \multirow{2}{*}{$\begin{array}{l}\text { Incidence } \\
\text { rate } \\
\end{array}$} & \multirow{2}{*}{$\begin{array}{l}\text { Median } \\
\text { ST year } \\
\end{array}$} & \multicolumn{2}{|c|}{ Cox Proportional Hazard Model } & \multicolumn{2}{|c|}{ Generalised Gamma Model } \\
\hline & & & HR95\% CI & aHR95\% CI & TR95\% CI & aTR95\% CI \\
\hline \multicolumn{7}{|l|}{ Age } \\
\hline $15-19^{\wedge}$ & 0.017 & 17 & & & & \\
\hline $20-24$ & 0.038 & 19 & $1.271 .19-1.36 *$ & $0.790 .74-0.85 *$ & $0.990 .97-0.99 *$ & $1.061 .05-1.07 *$ \\
\hline \multicolumn{7}{|l|}{ Sex } \\
\hline Male $^{\wedge}$ & 0.020 & 21 & & & & \\
\hline Female & 0.034 & 18 & $1.991 .87-2.11$ & $1.301 .21-1.39 *$ & $0.890 .88-0.9^{*}$ & $0.970 .95-0.98 *$ \\
\hline \multicolumn{7}{|l|}{ Zone } \\
\hline North Central & 0.028 & 19 & $1.121 .01-1.25 *$ & $0.940 .81-1.09$ & $0.980 .96-0.99 *$ & $1.010 .99-1.04$ \\
\hline North East & 0.029 & 19 & $1.221 .10-1.36^{*}$ & $0.830 .70-0.98 *$ & $0.960 .95-0.98 *$ & $1.041 .01-1.06 *$ \\
\hline North West & 0.030 & 19 & $1.301 .17-1.44^{*}$ & $0.890 .74-1.07$ & $0.940 .93-0.96 *$ & $1.020 .99-1.05$ \\
\hline South East & 0.019 & 21 & $0.720 .64-0.81 *$ & $0.880 .70-1.11$ & $1.061 .04-1.08 *$ & $1.020 .99-1.06$ \\
\hline South South & 0.035 & 18 & $1.571 .42-1.74 *$ & $1.561 .33-1.84 *$ & $0.920 .91-0.94 *$ & $0.930 .91-0.95 *$ \\
\hline South West^ & 0.025 & 20 & & & & \\
\hline \multicolumn{7}{|l|}{ Residence } \\
\hline Urban $^{\wedge}$ & 0.024 & 20 & & & & \\
\hline Rural & 0.030 & 19 & $1.371 .29-1.47 *$ & $1.101 .01-1.20 *$ & $0.940 .93-0.95 *$ & $0.980 .97-.99 *$ \\
\hline \multicolumn{7}{|l|}{ Economic status } \\
\hline Lowest & 0.031 & 19 & $1.491 .40-1.60 *$ & $1.191 .09-1.31 *$ & $0.920 .91-0.93 *$ & $0.970 .96-0.98 *$ \\
\hline Middle & 0.027 & 19 & $1.181 .09-1.28 *$ & $1.131 .04-1.23 *$ & $0.970 .96-0.98 *$ & $0.980 .97-0.99 *$ \\
\hline 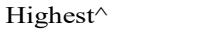 & 0.024 & 20 & & & & \\
\hline \multicolumn{7}{|l|}{ Education } \\
\hline No Education & 0.040 & 17 & $2.191 .95-2.45 *$ & $1.241 .08-1.42 *$ & $0.850 .83-0.86^{*}$ & $0.960 .94-0.97 *$ \\
\hline Primary/Qur'anic & 0.030 & 19 & $1.471 .31-1.66^{*}$ & $1.111 .07-1.15^{*}$ & $0.910 .89-0.93 *$ & $0.980 .97-0.99 *$ \\
\hline Secondary & 0.024 & 20 & $1.050 .95-1.17 *$ & $0.870 .78-0.97 *$ & $0.970 .95-0.98$ & $1.031 .01-1.05 *$ \\
\hline Higher^ & 0.022 & 20 & & & & \\
\hline \multicolumn{7}{|l|}{ Religion $^{c}$} \\
\hline Islam & 0.029 & 19 & $1.111 .04-1.18^{*}$ & $0.870 .80-0.96 *$ & & $1.021 .01-1.03 *$ \\
\hline Christian^ $^{\wedge}$ & 0.027 & 19 & & & & \\
\hline Others & 0.031 & 19 & $1.110 .84-1.48$ & $0.770 .58-1.03$ & & $1.030 .99-1.08 *$ \\
\hline \multicolumn{7}{|l|}{ Tribe $^{c}$} \\
\hline Hausa/Fulani & 0.030 & 19 & $1.721 .56-1.90^{*}$ & $1.100 .89-1.37$ & & $0.990 .96-1.02$ \\
\hline Yoruba^ $^{\wedge}$ & 0.020 & 21 & & & & \\
\hline Igbo/Ibiobio & 0.025 & 20 & $1.331 .19-1.49 *$ & $1.371 .10-1.70^{*}$ & & $0.950 .92-0.98 *$ \\
\hline Others & 0.031 & 19 & $1.761 .61-1.93 *$ & $1.170 .97-1.40$ & & $0.970 .95-0.99 *$ \\
\hline \multicolumn{7}{|l|}{ Marital status } \\
\hline Never Married $^{\wedge}$ & 0.018 & 22 & & & & \\
\hline Currently Married & 0.058 & 16 & $3.963 .73-4.20 *$ & $3.733 .46-4.01 *$ & $0.810 .72-0.89 *$ & $0.820 .81-0.83 *$ \\
\hline Formerly Married & 0.049 & 17 & $3.082 .44-3.90 *$ & $2.912 .29-3.68 *$ & $0.830 .80-0.86^{*}$ & $0.850 .82-0.88 *$ \\
\hline \multicolumn{7}{|c|}{ Age at 1st Marriage ${ }^{a}$} \\
\hline Never $^{\wedge}$ & 0.018 & 22 & & & & \\
\hline$<15$ & 0.069 & 14 & $12.210 .9-13.6 *$ & & $0.620 .51-0.76^{*}$ & \\
\hline $15-19$ & 0.061 & 16 & $5.184 .83-5.55^{*}$ & & $0.760 .68-0.89 *$ & \\
\hline $20+$ & 0.051 & 20 & $2.001 .81-2.20 *$ & & $0.930 .89-0.95 *$ & \\
\hline Total & 0.028 & 19 & & & & \\
\hline
\end{tabular}

\section{Discussion}

This study was designed to examine the timing of the progression of youths in Nigeria to sexual debut and to determine the factors affecting the timings. We found significant generational shift in the timing of sexual debut among individuals aged 15-19 years and those aged 20-24 years. In addition, we observed significant differences in timing of sexual debut by gender, rural-urban difference and geographical zone of residence, economic class, ed- ucational attainment as well as age at first marriage and ethnic divides of the respondents.

We found sexual activity to be very prevalent among the studied sub-population with age of sexual debut clustering around 17 years for both males and females, this was slightly higher than the 16 years reported in Nigeria in $2007^{25}$. This suggests that the campaign against early sexual debut in Nigeria might have began to yield results. However, we found median survival time for sexual de- 
but to be 19 years. This is similar to previous findings in other African countries ${ }^{1,3,12,21,37}$ but slightly lesser than 18-19 years reported in recent Canada and U.S studies ${ }^{7,26}$. It has been suggested that adolescents undergo "cognitive, emotional, sexual and psychological transformation" during early adolescence ${ }^{38}$. This often results in the adolescence having behavioural change and appearance to meet those of their peers hence the median age at sexual debut centering around 19 years.

Cumulatively, the proportion of females who had been engaged in sexual activities at each exact ages were higher than in males and also higher among the young adults than the teenage respondents. The rate at which the females get initiated into sexual activity on yearly basis outstretched the rate among males with an incidence rate of 0.034 versus 0.020 per annum. The females had higher odds of sexual debut than the males. Similar differences have been documented earlier ${ }^{2,26,39}$. This trend has made the females more exposed to risk of early sexual debut. The earlier sexual debuts among females has been ascribed to attainment of maturity earlier than males, having older sexual partners and having more financial challenges than males ${ }^{5,26,39}$.

Our analysis revealed that rural-urban differences in the residences of both males and females significantly affected the rate at which they assumed sexual experiences. We found female respondents living in rural areas to have higher probabilities of earlier sexual debut than the males as they grew older. This was in agreement with earlier reports elsewhere ${ }^{2,37,39}$. This could be ascribed to a less strict parenting as well as economic hardship in rural areas than in urban areas. The lower educational opportunities in rural areas can also explain the differences.

In this study, we found earlier sexual debut among females with no formal education and those with only primary education than their peers with secondary and higher education. This finding is similar to the rate of sexual debut experience among the males. Our findings are consistent with reports elsewhere that in-school adolescents and those with better education are more likely to delay sexual debut than the out-of-schools and the less educated ones ${ }^{1,4,10-12,16,40}$. This finding could be ascribed to more freedom among children in school than those not attending school. More so, early marriage which drives early sexual debut are commoner among persons with little or no education. While economic status was not signif- icant to rate of sexual debut among females, males having better economic status were found to generally delay the commencement of sexual activities. This is very intuitive because females, irrespective of social status, can be enticed with little monetary gifts by older male partners and get initiated to sexual activities unlike the males. We used adolescents' and youths' economic status as proxies for their parents' economic status which has been found to be correlated with parents' education and sexual risky behaviour among adolescents and young adults ${ }^{26,41}$. This indicated that economical means of parents do not influence timing of sexual debut in their female children unlike among males.

We found positive and direct correlations between age at first marriage and age at first sexual intercourse among males and females with youths who delayed marriage to be more likely to delay first sexual experience. A previous Ethiopian study corroborated this finding wherein the authors concluded that for most girls in Ethiopia, marriage is a major driver of sexual debut ${ }^{1}$. However, this position is contrary to earlier arguments by Wellings et al who reported worldwide shift towards later marriage has resulted in increased rate of pre-marital sex which has effect on age at first sex ${ }^{5}$. It may suffix to delay marriage if later sexual debut is desired since postponement of sexual intercourse would be nearly impossible within marriage.

Religion, ethnicity, geographical place of residence which influence socio-cultural differences were found in the current study to have also influenced age at first sexual experience. For instance, adolescents and youths in the South West region had the lowest likelihood of sexual debut than females from other zones. Similarly, Hausa/ Fulani respondents who are predominantly Muslims and among whom practice of child marriage is commoner, ${ }^{31,33}$ were more likely to be sexually initiated than Yoruba and Igbo respondents who were majorly Christians. This finding is in consonance with other reports that norms and social practices affect age at sexual debut $t^{5,26,35,32,33}$.

\section{Conclusion}

Findings of this study suggested diversities in sexual debut among adolescents and young adults although they both began sexual activities so early. Being female, married early, region and place of residence as well as poor educational attainment are the major drivers of sexual 
debut. In particular, female youths from poor households mostly in rural areas with little or no education and who married early in life were more likely to have early sexual debut than others. Both teenagers and young adults are on different trajectories of sexual debut but both urgently need sexual and reproductive health education to delay sexual debut so as to avert its health and economic consequences. In some circumstances, it may be necessary to postpone marriage so as to have a delayed sexual debut.

\section{Recommendations}

Sexuality is very complex; it is affected by combination of several factors ${ }^{22}$. It may therefore be risky and wasteful to address one factor and leave others unattended to. Policies to help delay sexual debut among youths should be put in place and must include sexual and reproductive health education and civic orientation for young people, their family and the communities at large. It is very imperative to ensure education for all youths right from childhood and to also introduce and strengthen sexual and reproductive health education early in school curriculums. The curriculum should be expanded to include dangers and consequences of early sexual activities. Parents and guardians should make sexuality an open discussion topic and discourage early sex although there could be concerns that such education and discussions may promote early sexual experimentation; but literature has confirmed that sex education does not necessarily push adolescents to sexual debut. Communities and families should discourage early marriage as this study suggested strong relationship between age at first marriage and first sex.

\section{Limitations}

This is a retrospective study with uncertainty of data accuracy. The data, especially the respondents' self-reported dates might have suffered recall bias as there was no means to verify them. Inclusion of respondents' characteristics such as whether the parents were living together, the types of family, number of siblings in the analysis would have been desirable but were not available due to secondary nature of the data. Research gaps exist on the role of community, parental marital status, migration and other factors on timing of sexual debut in Nigeria.

\section{Author's contribution}

AAF conceived and designed the study, formulated the hypothesis and wrote the methodology, analysed the data and wrote the result and discussion. ESI contributed to the discussion and facilitated the publication. Both authors reviewed final version of the manuscript.

\section{Conflict of interest}

The authors of this manuscript declared no conflict of interest.

\section{References}

1. Tilahun M, Ayele G. Factors associated with age at first sexual initiation among youths in Gamo Gofa, South West Ethiopia : a cross sectional study. BMC Public Health [Internet]. BMC Public Health; 2013;131:1-6. PubMed Available from: BMC Public Health DOI: 10.1186/1471-2458$13-622$

2. Welti K, Wildsmith E, Manlove J. Trends and Recent Estimates: Contraceptive Use Among U.S. Teens and Young Adults. Trends Res Br. 2011;23.

3. Finer ALB, Philbin JM. Sexual Initiation, Contraceptive Use, and Pregnancy Among Young Adolescents. Pediatrics. 2013;1315:1-6. PubMed DOI: /10.1542/ peds.2012-3495

4. Young H. Factors Associated with the timing of First Sex Among College Students. Korean J Androl. 2011;292:134. DOI: 10.5534/kja.2011.29.2.134 PubMed 5. Wellings K, Collumbien M, Slaymaker E, Singh S, Hodges Z, Patel D, et al. Sexual behaviour in context: a global perspective. Lancet Sex Reprod Heal Ser. 2006;10. PMID: 17098090

6. Wight D, Henderson M, Raab G. Extent of regretted first intercourse among young teenagers in Scotland: a cross sectional survey. BMJ. 2000;44:1245-;44. PubMed DOI:10.1136/bmj.320.7244.1243

7. The Sex Information and Education Council of Canada. The U.S. National Survey of Family Growth: Age at First Intercourse, Relationship to Partner, and Contraceptive Use. 2012.

8. Jennifer C, Wendy C. Mixed-gender groups, dating and romantic relationships in early adolescence. J Res Adolesc. 2004;142:185-207. PubMed DOI: 10.1111/j.15327795.2004.01402003.x

9. Centers for Disease Control and Prevention CDC. Trends in sexual risk behaviors among high school students- United States, 1991-1997. MMWR Morb Mortal Wkly Rep. 1998;4736:749-52. PMID: 18668019

10. Upadhyay U. The Determinants of the Progression to First Sex Among Adolescents in Cebu, Philippines. 2006; April.

11. Mitike M, Yemane B, Bernt L. Traditional values of 
virginity and sexual behaviour in rural Ethiopian youth: results from a cross-sectional study. BMC Publ Heal. 2008;89. PubMed DOI: 10.1186/1471-2458-8-9

12. Central Statistical Agency [Ethiopia] and ORC Macro. Ethiopia Demographic and Health Survey 2010. Addis Ababa, Ethiopia; 2011.

13. Ezire O, Oluigbo O, Archibong V, Ifeanyi O, Anyanti J. Barriers to repeated use of female condom among women and men of reproductive age in Nigeria. J AIDS HIV Res. 2013;56:206-13. PubMed DOI: 10.5897/ JAHR2013.0239

14. WHO. The Millenium Development Goals [Internet]. THe MDGs. 2012. Available from: http://www.who.int/ mediacentre/factsheets/fs290/en/

15. Eghieye IU. Maternal Mortality in Sub-Saharan Africa : Steps Towards Millennium Developmental Goals [Internet]. Texas: Fort Worth, Tx: University of North Texas Health Science Center; 2014. Available from: http:/ / digitalcommons.hsc.unt.edu/theses/764

16. Ekundayo OJ, Dodson-stallworth J, Roofe M, Inmaculada B, Bachmann LH, Kempf MC, et al. The Determinants of Sexual Intercourse Before Age 16 Years Among Rural Jamaican Adolescents. Sci World J. 2007;7:493-503. DOI 10.1100/tsw.2007.94

17. Salihu HM, Sharma PP, Ekundayo, O.J. Kristensen S, Badewa AP, Kirby RS, Alexander GR. Childhood pregnancy 10-14 years old and risk of stillbirth in singletons and twins. J Pediatr. 2006;1484:522-6. PMID:16647417

18. Allen I, Bourke DS. , Teenage Mothers: Decisions and Outcomes, London: Policy Studies Institute, 1998

19. FMoH. National HIV/AIDS and Reproductive Health and Serological Survey, 2012 NARHS Plus,. Federal Ministry of Health, Abuja, Nigeria; 2013.

20. HIV Disclosure To Children. HIV infection Rates Among Adolescents and Youth. [Internet]. 2015. Available from: http://www.hivdisclosuretochildren. org/2014-international-youth-day/

21. Shisana O, Rehle T, Simbayi L, Zuma K, Jooste S, Zungu N, et al. South African National HIV Prevalence, Incidence and Behaviour Survey, 2012 [Internet]. Cape Town; 2014. Available from: http://www.hsrc.ac.za/uploads/pageContent/4565/SABSSM IV LEO final.pdf

22. Stone N, Ingham R. Factors Affecting British Teenagers ' Contraceptive Use at First Intercourse : Perspect Sex Reprod Health. 2002;344:191-7. PMID:12214909

23. National Population Commission Nigeria and ICF International. Nigeria Demographic and Health Survey 2013. Abuja, Nigeria; 2014.
24. ChartsBin Statistics Collector Team. Average Age at First Sex by Country [Internet]. ChartsBin.com. 2009 [cited 2016 Apr 4]. p. 1-4. Available from: http://chartsbin.com/view/xxj

25. FMoH. National HIV/AIDS and Reproductive Health and Serological Survey, 2007 NARHS Plus. Federal Ministry of Health Nigeria, Abuja Nigeria; 2007.

26. Martinez G, Copen CE, Abma JC. Teenagers in the United States: sexual activity, contraceptive use, and childbearing, 2006-2010 National Survey of Family Growth. Vital Heal Stat. 2011;2331.

27. Riessing ED, Andruff HL, Wentland JJ. Looking back: the experience of first sexual intercourse and current sexual adjustment in young heterosexual adults. J Sex Res. 2011;491:27-35. PubMed DOI: 10.1080/00224499.2010.538951 PMID:21161815

28. National Population Commission Nigeria and ICF International. Nigeria Demographic and Health Survey, 2008. DHS Measure Macro, New York and Nigeria Population Commission, Abuja, Nigeria; 2009.

29. Kiernan KE. Becoming a young parent: a longitudinal study of associated. BrJ Sociol. 1997;483:406-28. PubMed 30. Attawell K. Going to Scale in Ethiopia: Mobilizing Youth Participation in a National HIV/AIDS Program. Washington DC; 2004.

31. Doctor H, Findley S, Afenyadu G, Uzondu C, Ashir G. Awareness, use, and unmet need for family planning in rural northern Nigeria. Afr J Reprod Heal. 2013;174:10717. PubMed PMID:24558787

32. Ashir GM, Doctor H V, Afenyadu GY. Performance Based Financing and Uptake of Maternal and Child Health Services in Yobe Sate, Northern Nigeria. Glob J Heal Sci. 2013;53:34-41. PubMed DOI:10.5539/gjhs. v5n3p34 URL

33. Adebowale SA, Fagbamigbe FA, Okareh TO, LawalGO. Survival Analysis of Timing of First Marriage among Women of Reproductive age in Nigeria : Regional Differences. AfrJ Reprod Health. 2012;164:95-107. PMID: 23444547

34. Kiernan KE, Hobcraft JN. Parental divorce during childhood: age at first intercourse, partnership and parenthood. Popul Stud NY. 1997;511:41-55. PMID: 9372635 35. Doctor H, Bairagi R, Findley SE, Helleringer S. Northern Nigeria Maternal, Newborn and Child Health Programme: Selected Analyses from Population-Based Baseline Survey. Open Demogr J. 2011;4:11-21.

36. Cox DR, Oakes. D. The Analysis of Survival Data. Hall. C and, editor. London: Chapman and Hall.; 1983. 
37. Mda P, O’Mahony D, Yogeswaran P, O’Mahony WG. Knowledge, attitudes and practices about contraception amongst schoolgirls aged 12-14 years in two schools in King Sabata Dalindyebo Municipality, Eastern Cape. Afr J Prm Heal Care Fam Me [Internet]. 2013;51. Available from: http://dx.DOI:10.4102/phcfm.v5i1.509

38. UNICEF. The state of the world's children: Adolescence, An Age of Opportunity. New York; 2011.

39. Wood K, Maepa J, Jewkes R. Adolescent sex and contraceptive experiences: perspectives of teenagers and clinic nurses in the Northern Province. Medical Research Council, SA. Johannesburg; 1997.
40. Fagbamigbe AF, Adebowale AS, Olaniyan FA. A Comparative Analysis of Condom Use Among Unmarried Youths in Rural Community in Nigeria. J Public health Res. 2011;11:8-16. PubMed DOI: 10.5923/j. phr.20110101.02

41. Fagbamigbe AF, Bamgboye EA, Yusuf BO, Akinyemi JO, Issa BK, Ngige E, et al. The Nigeria wealth distribution and health seeking behaviour : evidence from the 2012 national HIV / AIDS and reproductive health survey. 2015; DOI: 10.1186/s13561-015-0043-9 